\title{
A single QTL with large effect is associated with female functional virginity in an asexual parasitoid wasp
}

\author{
Wen-Juan $\mathrm{Ma}^{1,2} \odot$ | Bart A. Pannebakker ${ }^{3} \odot \mid$ Xuan $^{1} \mathrm{Li}^{1}$ | Elzemiek Geuverink ${ }^{1}$ |

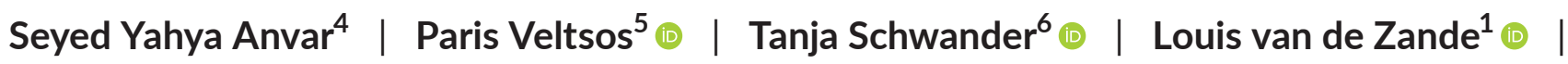 \\ Leo W. Beukeboom ${ }^{1}$
}

${ }^{1}$ Groningen Institute for Evolutionary Life Sciences, University of Groningen, Groningen, The Netherlands

${ }^{2}$ Department of Molecular Biosciences, University of Kansas, Lawrence, KS, USA

${ }^{3}$ Laboratory of Genetics, Wageningen University and Research, Wageningen, The Netherlands

${ }^{4}$ Department of Human Genetics, Leiden University Medical Center, Leiden, The Netherlands

${ }^{5}$ Department of Ecology and Evolutionary Biology, University of Kansas, Lawrence, KS, USA

${ }^{6}$ Department of Ecology and Evolution, University of Lausanne, Lausanne, Switzerland

\section{Correspondence}

Wen-Juan Ma, Department of Molecular Biosciences, University of Kansas, Lawrence, KS, USA.

Email:wenjuanma84@gmail.com

Funding information

Ubbo Emmius Fellowship from the University of Groningen; China Scholarship Council (CSC), Grant/ Award Number: 201606330077; Netherlands Organization for Scientific Research (NWO), Grant/Award Number: 854.10.001 and 824.15.015

\begin{abstract}
During the transition from sexual to asexual reproduction, a suite of reproductionrelated sexual traits become superfluous, and may be selected against if costly. Female functional virginity refers to asexual females resisting to mate or not fertilizing eggs after mating. These traits appear to be among the first that evolve during transitions from sexual to asexual reproduction. The genetic basis of female functional virginity remains elusive. Previously, we reported that female functional virginity segregates as expected for a single recessive locus in the asexual parasitoid wasp Asobara japonica. Here, we investigate the genetic basis of this trait by quantitative trait loci (QTL) mapping and candidate gene analyses. Consistent with the segregation of phenotypes, we found a single QTL of large effect, spanning over $4.23 \mathrm{Mb}$ and comprising at least 131 protein-coding genes, of which 15 featured sex-biased expression in the related sexual species Asobara tabida. Two of the 15 sex-biased genes were previously identified to differ between related sexual and asexual population/species: CD151 antigen and nuclear pore complex protein Nup50. A third gene, hormone receptor 4 , is involved in steroid hormone mediated mating behaviour. Overall, our results are consistent with a single locus, or a cluster of closely linked loci, underlying rapid evolution of female functional virginity in the transition to asexuality. Once this variant, causing rejection to mate, has swept through a population, the flanking region does not get smaller owing to lack of recombination in asexuals.
\end{abstract}

\section{KEYWORDS}

asexuality, candidate genes, female functional virginity, introgression, linkage map, loss of sex, resistance to mating, single major QTL

\section{1 | INTRODUCTION}

A suite of reproduction-related sexual traits become superfluous during the transition from sexual to asexual reproduction (Carson et al., 1982; Jeong \& Stouthamer, 2005; Kraaijeveld et al., 2009, 2016; Kremer et al., 2009; Ma et al., 2014a; Pannebakker et al.,
2005; Parker et al., 2019; Russell \& Stouthamer, 2011; Schwander et al., 2013). Asexual females do not require mating with males for offspring production, and produce only daughters. As a consequence, costly sexual traits are expected to be selected against in asexual lineages (Ma et al., 2014b; van der Kooi \& Schwander, 2014). Consistent with this expectation, there is good evidence for rapid 
reduction of sexual traits in asexual females, especially of traits linked to mate attraction and copulation, which are believed to be particularly costly in many species (Schwander et al., 2013; van der Kooi \& Schwander, 2014).

Traits reducing mate attraction or copulation probability are of particular interest in hymenopteran insects, where they have been referred to as "female functional virginity" (Huigens \& Stouthamer, 2003; Jeong \& Stouthamer, 2005; Russell \& Stouthamer, 2011; Stouthamer et al. 2010). In hymenopterans, virgin sexual females produce only sons, because sex determination relies on haplodiploidy (males develop from unfertilized, haploid eggs, females from diploid eggs) (Whiting, 1933). In many species, parthenogenesis is induced by endosymbionts, such as Wolbachia, Cardinium and Rickettsia (Ma et al., 2014b; Ma \& Schwander, 2017). During the initial infection stage, an increasing number of asexual females cause sex ratios to become largely female biased. Infected females still can mate and fertilize their eggs in the initial infection stage, as found in Trichogramma wasps (Stouthamer \& Kazmer, 1994). The female-biased sex ratio would then select for increased production of male offspring. Under haplodiploidy, an all-male progeny is produced when uninfected females remain virgin or mated females do not use stored sperm to fertilize their eggs. The mutations that increase production of male offspring were thus referred to as "female functional virginity" mutations (Huigens \& Stouthamer, 2003; Stouthamer et al., 2010). These mutations will then spread into the infected population via matings between carrier males and infected females.

Reduced sexual traits associated with female functional virginity have been reported in at least six different asexual hymenopteran species (Gottlieb \& Zchori-Fein, 2001; Jeong \& Stouthamer, 2005; Ma et al., 2014a; Pannebakker et al., 2005; Pijls et al., 1996; Russell \& Stouthamer, 2011; Stouthamer et al., 2010). The genetic and molecular basis underlying female functional virginity remains elusive, which is in part due to the inability to perform crosses in asexual organisms. However, crosses are possible in some hymenopteran asexual species, because asexuality is caused by infection with maternally transmitted endosymbionts, such as Wolbachia. When asexual females are cured from their endosymbionts via antibiotic treatment, they produce males and these males can be mated to females from related sexual strains (Jeong \& Stouthamer, 2005; Ma et al., 2014a; Pannebakker et al., 2005; Russell \& Stouthamer, 2011). The current evidence of the genetic mechanisms resulting in female functional virginity in asexual hymenopterans points to mutations in few genes with relatively strong phenotypic effects (reviewed in van der Kooi \& Schwander, 2014), although these results may be biased by the Beavis effect, which postulates an overestimation of QTL effect sizes when sample size is small (Beavis, 1994).

Asobara japonica is a parasitic wasp with both sexual and allfemale asexual populations that are geographically separated. Asexual populations are distributed across mainland Japan, whereas sexual populations largely occur on southern islands (Murata et al., 2009). A. japonica, like all hymenopterans, has haplodiploid reproduction (Giorgini et al., 2010; Kageyama et al., 2012; Leach et al., 2009; Ma et al., 2014a; Werren, 1997; Werren et al., 2008). Asexuality in A. japonica is induced by the bacterial endosymbiont Wolbachia, and unfertilized haploid eggs laid by endosymbiont-infected females typically undergo diploidization and develop as females. Sexual populations are devoid of Wolbachia (Kremer et al., 2009; Reumer et al., 2012). A previous study has shown no variation between the Wolbachia strains in five asexual populations of A. japonica (Kraaijeveld et al., 2011), suggesting that the Wolbachia infection in this species is relatively young. Given the divergence between two large groups of mitochondial haplotypes in the parasitoid wasp, it was estimated that Wolbachia infection occurred between $8.2 \times 10^{5}$ and $2.2 \times 10^{5}$ generations (approximately 300,000-70,000 years) ago (Reumer et al., 2012). Removing the infection by antibiotic treatment results in the production of haploid males from unfertilized eggs. Asexual females also occasionally produce haploid males under natural conditions (Heath et al., 1999; Reumer et al., 2012). Although these males usually do not have any mating opportunities in nature, in the laboratory they can be mated with females of sexual strains.

A previous study in A. japonica revealed that asexual females are less attractive than sexual females, and completely refuse to mate (Ma et al., 2014a). Female functional virginity in asexual A. japonica is thus probably governed by genes mediating female mating propensity. Introgression of alleles from an asexual strain into a sexual one for four consecutive generations revealed that a single recessive locus with major effects caused introgressed females to produce only haploid sons, suggesting a relatively simple genetic architecture for female functional virginity (Ma et al., 2014a).

In the current study we identified the genomic regions and possible candidate genes associated with female functional virginity in A. japonica. We genotyped the sex-asex introgressed females that were previously analysed for resistance to mating and produce only haploid sons (Ma et al., 2014a). We constructed a genetic map, a genome assembly of $A$. japonica from PacBio long reads sequencing, and subsequently performed a quantitative trait loci (QTL) analysis. In addition, Illumina short-reads of sexual and asexual strains of $A$. japonica, and a transcriptome data set of the sexual species Asobara tabida, were used to infer candidate genes.

\section{2 | MATERIALS AND METHODS}

\subsection{Wasp strains and culturing}

A sexual and a Wolbachia-infected, asexual strain of Asobara japonica were used. The sexual strain originated from the Amami-Oshima island $(\mathrm{AO})$ and the asexual strain from Kagoshima (KG), both in Japan, and have been cultured in the laboratory since 2009. These two strains are closely related (Murata et al., 2009; Reumer et al., 2012), which minimizes the probability of genetic incompatibility in crosses. A. japonica was cultured on second-instar Drosophila melanogaster larvae as hosts at $25^{\circ} \mathrm{C}$, with a $16 \mathrm{~L}$ : $8 \mathrm{D}$ light-dark cycle and $60 \%$ relative humidity (for details see Ma et al., 2013, 2014a).

Sons from asexual females (so called "asexual" males) were obtained by antibiotic treatment of Wolbachia-infected females (see below) or directly collected from mass cultures in which males occur 
at low frequency (i.e. $~ 0.7 \%, N=6,000$ individuals). As spontaneously occurring males are sometimes diploid (Ma et al., 2015), flow cytometry was used to ensure that all males used in experiments were haploid (for details see Ma et al., 2013).

Antibiotic treatment (to obtain "asexual" males) was performed by providing Wolbachia-infected females with Drosophila hosts cultured on food containing $10 \mathrm{mg}$ of rifampicin for $1 \mathrm{~g}$ yeast powder (see Ma et al., 2014a). Rifampicin reduces the Wolbachia titre, but has little impact on development in Asobara (Dedeine et al., 2001). Complete removal of Wolbachia was confirmed by the production of only male offspring by the treated females.

\section{2 | Introgression cross design}

To investigate the genetic basis of female functional virginity, measured as females producing haploid sons only, asexual KG males were mated to virgin sexual $A O$ females in the first generation, and then to introgressed F1 females for three consecutive generations (details in Ma et al., 2014a; Figure 1b). Briefly, virgin females were collected by individually isolating wasp pupae in plastic vials (diameter $2.4 \mathrm{~cm}$, height $7.5 \mathrm{~cm}$ ) containing a layer of agar to control humidity (Ma et al., 2013). These virgin females were individually paired with a male from the asexual strain for $24 \mathrm{~h}$, and subsequently offered approximately $100 \mathrm{~s}$-instar D. melanogaster larvae for oviposition for $36 \mathrm{~h}$. The resulting wasp pupae were isolated from parasitized hosts to prevent mating upon emergence. Females emerging from these pupae (the F1 generation) were collected and backcrossed to males of the asexual KG strain, by individual pairing, to produce the offspring of the next generation (Ma et al., 2013, 2014a).

Under this cross design, the proportion of asexual alleles in females of each generation is expected to increase from $50 \%$ in $\mathrm{F} 1$, to $75 \%$ in BC2, $87.5 \%$ in BC3 and a $93.8 \%$ in BC4 (Ma et al., 2014a; Figure $1 \mathrm{~b})$. For each backcross, the emerging wasps were anaesthetized with CO2, counted and sexed (Ma et al., 2013, 2014a). For each backcross generation, a subset of introgressed females $(N=49-225$ depending on the generation) was sampled from the introgression experiment to determine their offspring sex ratio, by pairing a single female with a sexual male for $24 \mathrm{~h}$ and allowing $36 \mathrm{~h}$ for oviposition. Each female was scored for production of exclusively male or male and female offspring. The thus obtained binomial trait was used as the phenotype for QTL mapping.

\section{3 | Genome-wide SNP markers development}

To enable genetic analysis, SNP markers were generated from Illumina short reads of 30-pooled individuals of both the sexual

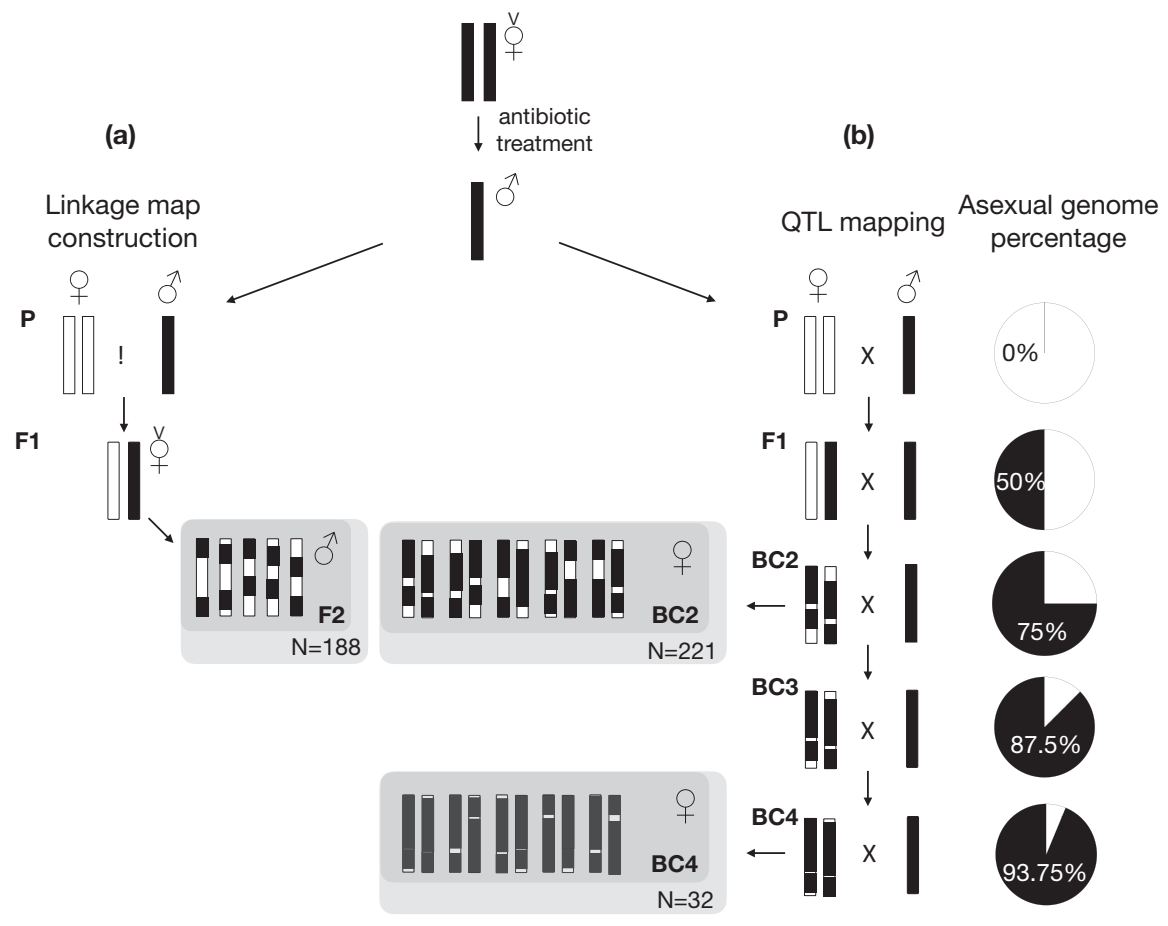

FIGURE 1 Cross schemes used to generate F2 recombinant males for linkage map construction (a), and four generations of backcrosses for QTL mapping of the female functional virginity trait (b). The AO sexual female (white) is crossed to the KG asexual male (black) to generate F1 females that were set up as virgins to produce recombinant F2 males. The F2 males (a) in grey shade were used for genotyping and linkage map construction, and females from backcross generation 2 (BC2) and 4 (BC4) (b) in grey shade were used for determining female mating success and QTL mapping. Black and white mosaic bars denote relative component of sexual and asexual genomes in consecutive generations. The pie chart shows the percentage of asexual genome component (in black) in diploid females in consecutive introgressed generations (modified from Ma et al., 2014a) 
AO and asexual KG strains (BioProject: PRJNA661661, accession number: SRR12618696-SRR12618699). Genomic DNA was extracted with a modified high-salt protocol (adjusted from Aljanabi \& Martinez, 1997, see details in the next section). DNA libraries were prepared at the University Medical Center Groningen Sequencing Facility and sequenced on an Illumina HiSeq2000. SNP markers were developed from the Illumina short reads using the de novo genomewide DIAL (De novo Identification of ALleles) computational pipeline, which identifies SNPs between two closely related genomes without needing a reference genome (Ratan et al., 2010). To prevent long CPU times, only a subsample of the reads $(1,172.5 \mathrm{Mb}$ or $3.9-4.2 \mathrm{x}$ coverage of the estimated wasp genome of 282-304 Mb, see K-mer analysis below) were analysed. The DIAL pipeline first removes duplicate reads and builds a short consensus sequence (ranging from 95 to $300 \mathrm{bp}$ ), which it then aligns to reads from previous runs to form clusters. Clusters with few nucleotide differences are selected and putative SNPs are detected and filtered based on the read quality at the variant position (minimum Phred-quality score used was 20).

The DIAL pipeline initially generated a database of 21,976 SNPs with their flanking region sequences and information about coverage depth and phred-quality scores for each of the two strains. The SNP coverage ratio $R$ is defined as the DIAL-generated coverage depth (d_SNP) of the SNP nucleotide, divided by the average coverage depth (d_reads) of the selected reads (against the estimated genome size): $R=d_{-}$SNP/d_reads. Following author recommendations (Ratan et al., 2010), only markers with $R>1.5$ were selected for further verification ( $n=10,001)$. Next, minimum coverage three and minimum base pair quality score 30 were used for further filtering which resulted in 951 remaining SNPs. Lastly, mitochondrial, bacterial and human homologous fragments were removed from the candidate SNP cluster list based on the BLAST results from NCBI sequence database, yielding 420 usable SNPs of which 130 were randomly selected for linkage map construction.

A subset of these 130 SNPs (57) was tested for amplification in both strains with primer pairs designed with Perlprimer (version 1.1.21, Marshall, 2004, Table S1) and Sanger sequenced (see below). This yielded 47 confirmed SNPs, to which another 66 randomly selected SNPs from the filtered SNP pool were added, for a total of 113 SNPs to be used for in the linkage map and QTL analyses.

The Illumina short reads ( $K G$ and $A O$ strains) were also used for estimating the genome size for each strain of $A$. japonica (KG: 281-304 Mb; AO: $280-284 \mathrm{Mb}$ ). The genome size was estimated by fitting the k-mer distribution of the Illumina short reads, obtained from JELLYFISH v2.1.0 (Marçais \& Kingsford, 2011), using GeNOMEScope v2 (http://qb.cshl.edu/ genomescope/genomescope2.0/) (Vurture et al., 2017), with recommended k-mer size of 21 (jellyfish count -m 21 -o fastq.counts -C -s 500000000 -t 5 Genome_R1.fastq GenomeR2.fastq).

\subsection{Genotyping and linkage map construction}

A cross between the sexual and asexual strains was set up to construct a linkage map for QTL mapping (Figure 1a). Virgin sexual
AO females were individually crossed to asexual KG males $(n=20)$ and provided with 100 hosts for oviposition (Figure 1a). After approximately two weeks, wasp pupae were isolated to collect virgin F1 females $(n=23)$ that were again offered 100 hosts for oviposition. Recombinant F2 (haploid) males $(n=188$ ) were collected and stored at $-80^{\circ} \mathrm{C}$ until DNA extraction and genotyping. DNA was extracted using a modified high salt protocol (adjusted from Aljanabi \& Martinez, 1997). In short, each wasp was homogenized in a $1.5 \mathrm{ml}$ Eppendorf tube with homogenization buffer $(0.4 \mathrm{M}$ $\mathrm{NaCl}, 10 \mathrm{mM}$ Tris: $\mathrm{HCl}$ pH 8.0, 2 mM EDTA) using a plastic pestle. After adding proteinase $\mathrm{K}$, the tissue was incubated overnight at $55^{\circ} \mathrm{C}$. After isopropanol precipitation, the DNA was dissolved in $20 \mu \mathrm{l} M Q$ water.

The 188 F2 males were genotyped for the 113 SNPs using the high-throughput Kompetitive Allele-Specific PCR robot genotyping system (KASP, Semagn et al., 2014) at the Institute of Biology Leiden (The Netherlands). Two allele-specific forward primers with a single difference at the SNP nucleotide position, and one common reverse primer (Table S2), were designed for each SNP fragment sequence. Each forward primer is attached to a unique unlabelled tail sequence at the $5^{\prime}$ end ( $15 \mathrm{bp}$ ) which can be detected by fluorescence (Semagn et al., 2014).

The initial genotyping data set was first cleaned up by removing SNPs with $>50 \%$ missing genotypes, which resulted in 96 suitable SNPs for linkage mapping. MAPDISTO software (version 1.7.7; Lorieux, 2012) was used to construct the genetic linkage map using the "BC" (backcross) population type setting to accommodate the haplodiploid sex determination system and cross design (Figure 1a). The "autoripple" function was used to order the loci per linkage group. Kosambi's mapping function (Kosambi, 1943) was used to translate recombination fractions into map distances. The linkage map was visualized with MAPCHART (version 2.2, Voorrips, 2002).

\section{5 | QTL mapping}

In total, $221 \mathrm{BC} 2$ and $32 \mathrm{BC} 4$ introgressed females were genotyped for the 96 SNP markers using the KASP platform. DNA was extracted from homogenized whole bodies with a Qiagen DNeasy kit after overnight treatment with $10 \%$ proteinase $\mathrm{K}$ (Qiagen) at $56^{\circ} \mathrm{C}$. The samples were processed on a BioSprint 96 workstation (Qiagen) with standard BS 96DNA program, resulting in 200 ul Buffer AE (Qiagen) DNA elution.

QTL analyses were conducted in the $\mathrm{R}$ package R/qtl $\vee 1.46-2$ (Broman \& Sen, 2009; Broman et al., 2003). The genotype data were converted to the backcross format, with homozygotes encoded as "AA" and heterozygotes as "AB" (Table S3) (Broman \& Sen, 2009). Duplicated markers were identified and removed with the "findDupMarkers" function. After removing markers with no genotype data, 92 markers remained. For each G2 or G4 recombinant female ( $n=253$ in total), the probability of the allelic state at every map position, conditional to the observed genotype for the segregating 
SNP markers, was estimated with a hidden Markov model, allowing for 0.001 genotyping error rate and missing genotype data. The genetic map was also re-estimated from the backcross by the LanderGreen algorithm (hidden Markov model) for further QTL analysis using R/QTL (Broman \& Sen, 2009, Figure S1). QTLs for the female functional virginity were identified by Haley-Knott regression (HK) or the expectation maximization (EM) algorithm (Haley \& Knott, 1992). The G2 and G4 generations were analysed jointly. Function "scanone" was run first for a binary model using 1,000 permutations, and generation as a covariate. A $5 \%$ threshold of logarithm of the odds (LOD) was applied in both methods. The "FIND.MARKER" function was then used to identify the closest markers to the QTL and calculate the phenotypic effects of the markers on either side of the QTL using the function "EFFECTPLOT". The 95\% confidence interval of the QTL region was calculated with function "BAYESINT". Finally, a linear regression, generalized linear model (GLM, y Generation +QTL + Generation:QTL, generation and the interaction with QTL were not significant), was applied to investigate the effect of generation and an interaction between generation and the QTL (see details in Results section), and to estimate the percent of phenotypic variance explained by the QTL.

\subsection{Genome assembly and annotation}

We assembled the genome of the asexual KG strain of $A$. japonica using PacBio long-read Single-Molecule-Real-Time (SMRT) sequencing (BioProject: PRJNA661661, accession number: JADHZF000000000). The mechanism of asexuality in this species is probably gamete duplication, which causes genome-wide homozygosity (Ma, 2014). As expected, homozygosity estimates obtained with JeLLYFISH v2.1.0 (Marçais \& Kingsford, 2011) were extremely high (98.4\%-100\%). Samples of 50 milligrams of asexual KG females (approximately 120 individuals) were used for DNA extractions with Genomic-tip 100/G (Qiagen) according to the manufacturer's protocol. A single library was constructed with SMRTBELL, and BLuePIPPIN was used to select the $>10 \mathrm{~kb}$ long fragments. The library was run on 30 PacBio RSII cells. In total 2,189,795 (postfilter) reads were obtained, representing an approximate coverage of $94 \mathrm{x}$. PacBio reads were then de novo assembled with FALCON (v0.2.2) with default parameters for insect data sets, but with modifications to fit our study species (Chin et al., 2016), i.e. length_cutoff_pr $=12,000$, pa_HPCdaligner_option $=-\mathrm{v}-$ dal128 -t16 -e0.75 -M24 -14800 -k18 -h480 -w8 -s100, pa_Dbsplit_option $=-x 500-$ s400, falcon_sense_option $=-$-output_multi - min_idt 0.70 -min_cov 5 -max_n_read $200-n_{-}$core 8 . The draft genome was then polished with QUIVER (2.2.1) (Chin et al., 2013). The quality and summary statistics of the assembled genome were analysed with QUAST v4.6.3 (Gurevich et al., 2013). BUsco3 was used to estimate the completeness of the assembled PACBIO KG genome (Simão et al., 2015).

RNAseq data sets originally generated for a different study were used to annotate the KG genome. These data sets were obtained from ovary tissues of both sexual and asexual A. japonica strains. Long-read SMRT sequencing of RNA was conducted on 100 pooled ovaries of asexual KG females, and ovaries from sexual females of the population IR (Iriomote-jima island Japan, Murata et al., 2009). Dissected ovaries were disrupted in Trizol (Invitrogen) and transferred to phase lock gel tubes. $200 \mu \mathrm{l}$ chloroform was added to the $1 \mathrm{ml}$ Trizol solution, shaken for $15 \mathrm{~s}$ and centrifuged for $10 \mathrm{~min}$ at $12,000 \mathrm{~g}$ at $4^{\circ} \mathrm{C}$. The resulting upper layer was transferred to the gDNA Eliminator spin columns of the RNeasy Plus Micro Kit (Qiagen) and further RNA extraction proceedings followed the kit protocol. The Teloprime (Lexogen) method was used to synthesize and amplify full-length cDNA. The library was constructed with SMRTBELL and sequenced on two cells of the PacBio Sequel. High-quality circular consensus sequences were used to identify full-length mRNA sequences, based on the presence of the primers and polyA sequences. ISOSEQ PIPELINE (v3) was then used to perform the analysis and polish isoform sequences (Gordon et al., 2015). The high-quality isoform sequences were subsequently aligned with GMAP against the PACBı genome assembly of the KG strain (Wu \& Watanabe, 2005). Finally, the generated transcriptome was functionally annotated with BLAST2Go v4.1 (Götz et al., 2008).

\section{7 | Candidate gene analysis}

Our QTL mapping approach uncovered a large QTL peak spanning over at least $4.23 \mathrm{Mb}$ of the A. japonica genome assembly, in two nonoverlapping contigs (see results). To obtain a list of candidate genes in this region, we used the original annotations from the PacBio genome (based on A. japonica transcriptomes from ovary tissue), and improved these using publicly available transcriptomes of three parasitoid wasp species (Diachasma alloeum, Fopius arisanus, and Microplitis demolitor; NCBI BioProject accession numbers: PRJNA284396, PRJNA259570, PRJNA214515 respectively) to ensure genes not expressed in ovaries were included. We were able to annotate 131 candidate genes in the QTL region (see results).

We hypothesized that female resistance to mating may be a female-specific trait and be regulated by genes featuring sex-biased expression. We screened all (131) candidate genes for sex-biased expression in a data set of the sexual sister species $A$. tabida, which was originally generated for a different purpose. The A. tabida data set was obtained by extracting RNA from whole-bodies of male and female A. tabida, with TriZol (Invitrogen) according to manufacturer's protocol. Individual RNA extractions of 11 females were pooled for one female library, and of 25 males for one male library. RNA libraries were prepared and sequenced on the Illumina HiSeq2000 at the UMCG Sequencing Facility. In total, 20.2 million and 26.6 million reads were retained in the female and male libraries respectively (BioProject: PRJNA661661, SAMN16067724, SAMN16067725), after the trimming step to remove adaptors and low quality reads using TRIMMOMATIC v0.33 with default parameters (Bolger et al., 2014). 


\begin{tabular}{|c|c|c|c|c|c|}
\hline Generation & $\begin{array}{l}\text { Percentage of } \\
\text { asexual genome }\end{array}$ & $\begin{array}{l}\text { Sample } \\
\text { size }\end{array}$ & $\begin{array}{l}\text { No. of } \\
\text { successful } \\
\text { matings }\end{array}$ & $\begin{array}{l}\text { No. of } \\
\text { failed } \\
\text { matings }\end{array}$ & $\begin{array}{l}\text { Percentage of } \\
\text { successful matings }\end{array}$ \\
\hline $\begin{array}{c}\text { G0 (sexual } \\
\text { strain) }\end{array}$ & $0 \%$ & 56 & 50 & 6 & $89.29 \%$ \\
\hline $\mathrm{F} 1$ & $50 \%$ & 49 & 46 & 3 & $93.88 \%$ \\
\hline $\mathrm{G} 2$ & $75 \%$ & 225 & 121 & 104 & $53.78 \%$ \\
\hline G3 & $87.50 \%$ & NA & NA & NA & NA \\
\hline G4 & $93.75 \%$ & 51 & 21 & 30 & $41.18 \%$ \\
\hline $\begin{array}{c}\text { GO (asexual } \\
\text { strain) }\end{array}$ & $100 \%$ & 20 & 0 & 20 & $0.00 \%$ \\
\hline
\end{tabular}

TABLE 1 Females rejecting matings over successive generations of introgression of the asexual genome into the sexual genome in Asobara japonica

Sample sizes, number and proportion of successful and failed matings for four consecutive generations (Ma et al., 2014a, 2014c).

We performed de novo transcriptome assembly with TRINITY $v$ 2.4.0 using default parameters (Haas et al., 2013), and performed differential gene expression analysis between sexes with the $R$ package EDGER v3.4 (Robinson et al., 2010; McCarthy et al., 2012; Chen et al.,2016 ). The details of differential expression analysis was described previously (Ma, Veltsos, Toups, et al., 2018; Ma, Veltsos, Sermier, et al., 2018). Briefly, the trimmed reads of the female and male sample were mapped to the assembled transcriptome with Kallisto v.0.43.0 (Bray et al., 2016). Read counts of the output from KALLISTO mapping were imported for gene expression analysis in EDGER v3.4 (McCarthy et al., 2012; Robinson et al., 2010) and filtered with average $\log _{2}(C P M)>0$ per sample, followed by normalizing the expression by trimmed mean $M$ values (TMM). Normalized expression counts for each sample were used to calculate sex bias using standard measures and Benjamini-Hochberg correction for multipletesting with false discovery rate (FDR) of $5 \%$. As we did not have biological replicates, the recommended dispersion value 0.4 was used in EDGER (Chen et al., 2016), and stringent criteria were applied when calling sex bias ( $\left|\log _{2} F C\right| \geq 2$, or fold change $\geq 4$ ).

One candidate gene out of 15 with differential expression between the sexes in A. tabida, hormone receptor 4, was analysed in further detail because of its suggested role in mating behaviour. To compare the gene sequences between sexual and asexual strains of $A$. japonica, we mapped the Illumina short reads of the sexual $\mathrm{AO}$ strain against the PacBio genome using bwa mem with default settings (Li \& Durbin, 2009). Before and after read filtering, read mapping quality was assessed with SAMTOOLS (v1.3) FLAGSTAT function (Li et al., 2009), and filtered by quality threshold $>20$. SNP calling was conducted on the mapped SAM files with BCFTools (v1.7, Narasimhan et al., 2016), and mapped reads with mapping depth coverage below three and above 80 were filtered out. Final SNPs were then called with vcfutils.pl scripts from BCFToots (v1.7) and plotted with a 500 bp sliding window for the two QTL contigs using GGPLOT2 in R (v3.6.3, R Core Team, 2020).

\section{3 | RESULTS}

\subsection{Female functional virginity}

We previously documented that asexual females of $A$. japonica rejected all mating attempts when confronted with males (Ma et al. 2014a). We classified this female resistance to mating as representing female functional virginity (sensu Huigens \& Stouthamer, 2003). To determine the genetic basis of female functional virginity, we previously introgressed alleles from the asexual KG strain into the sexual AO strain for four consecutive generations (summarized in Table 1, see also Ma et al., 2014a). In the present study, females from these same introgression generations were used for QTL analysis.

\section{2 | Linkage map construction}

The DIAL pipeline initially identified 21,976 SNPs, and a series of filtering steps led to 420 SNPs for further testing and selection (see Methods for details). Eventually, a set of 96 SNPs was used to construct a linkage map from the genotypes of 188 F2 haploid males (Figure 2). Linkage groups were determined with a minimum LOD score of 3 and a maximum recombination frequency of 0.35 between the linked pairs of SNP markers. After this first mapping, the double recombinants were used to identify potential genotyping errors with an error detection $p<.05$. Using this threshold, 25 erroneous candidates were removed which were coded as missing data. Next, Chi-square tests were used to check for segregation distortion from Mendelian expectations (1:1 for haploid F2 males). Segregation distortion was observed for $13.5 \%$ of SNP markers (13 out of 96, Chi-square test, $p<.05$ ), nine SNPs were skewed to the asexual genome and four to the sexual genome. Interestingly, one linkage group (LG7) consisted of seven markers that all significantly deviated from Mendelian expectations, with the asexual genome variant

FIGURE 2 Genetic linkage map of Asobara japonica. For each linkage group, the relative position (centimorgans) is indicated on the left side and the SNP markers are shown on the right side. ${ }^{* *} p<.01,{ }^{*} p<.05$ in chi-square tests for segregation distortion. LG, linkage group 
LG1

LG2

LG4

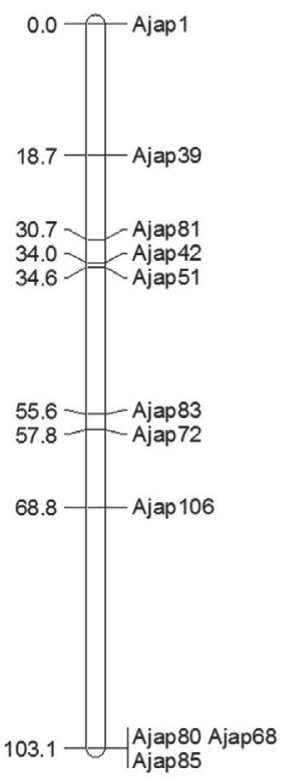

LG7

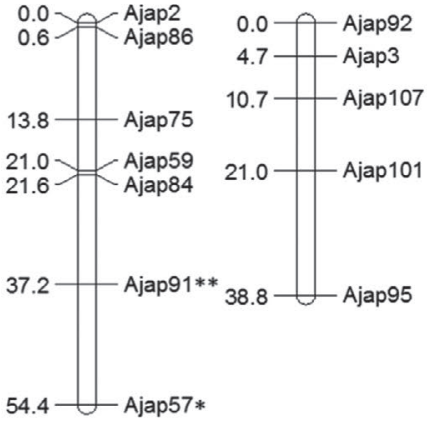

$54.4-$ Ajap57*
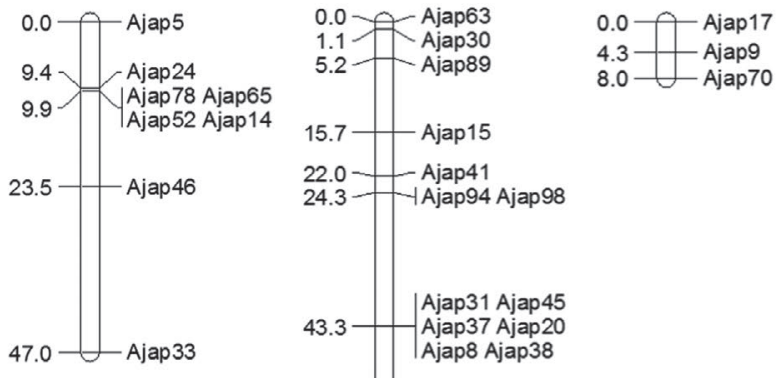

LG5

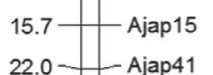

\begin{tabular}{l|l}
$22.0-1$ & Ajap41 \\
24.3 & - Ajap94 Ajap98
\end{tabular}

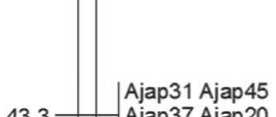

43.3- - Ajap37 Ajap20

Ajap8 Ajap38

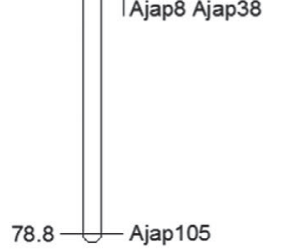

LG6

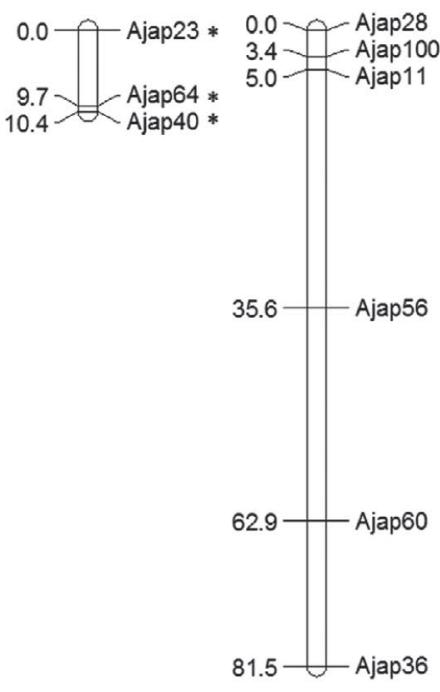

LG13

0.0 Ajap27

1.2 $\mathcal{C}_{\text {Ajap55 }}$
LG8

LG9

LG10

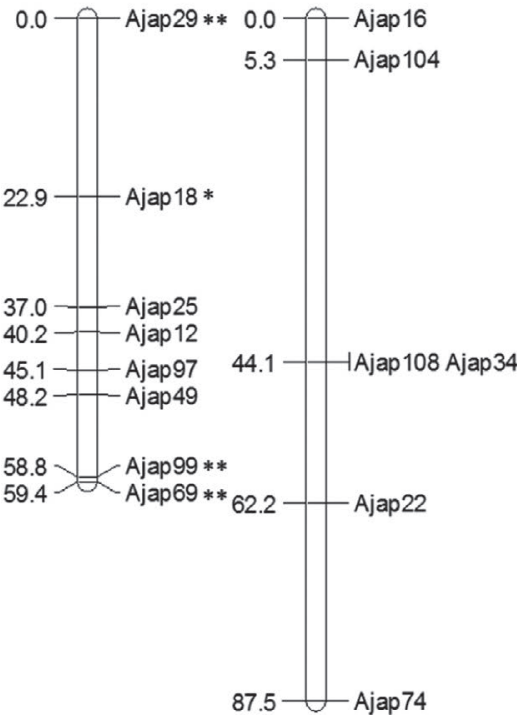

LG15

LG16
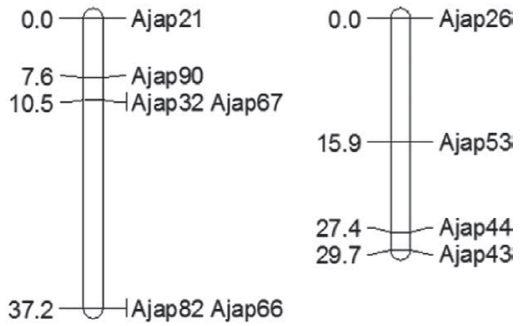

$29.7-$ Ajap43

LG11

LG12

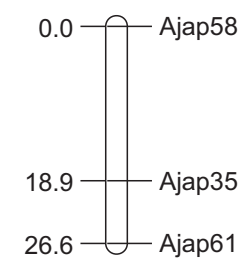

$0.0-\bigcirc-$ Ajap47 Ajap54

$0.0-$ Ajap96

Ajap61 


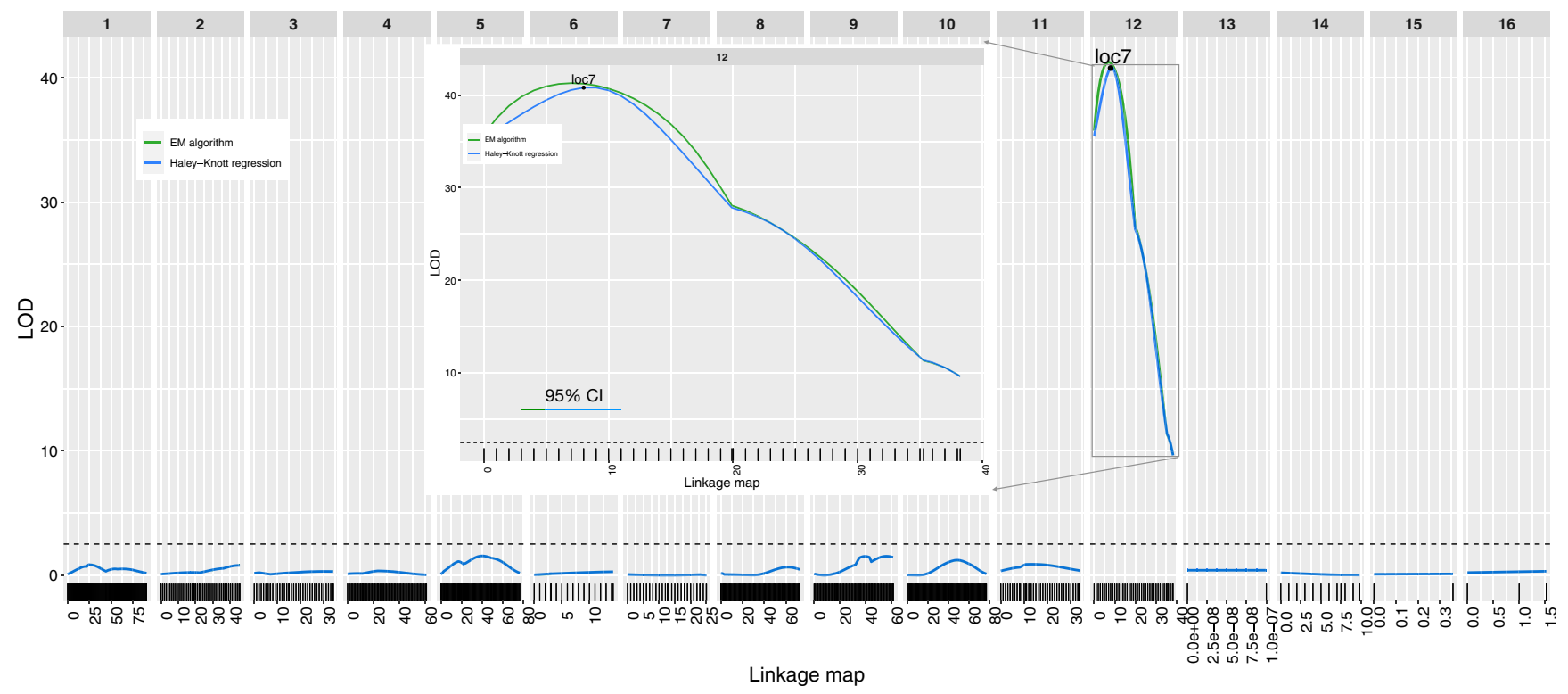

FIGURE 3 A single QTL for female functional virginity in A. japonica. The horizontal line corresponds to the $5 \%$ genome-wide significant threshold from permutation tests. The inserted figure shows $95 \%$ confidence interval for the detected QTL at LG12, with a range of 4-10 cM for expectation maximization (EM) and 6-11 cM for Haley-Knott regression (HK) method. LG, linkage group

being more common than expected. Four of the seven markers with the most extreme segregation distortion $(p<.000001)$ were removed from LG7 to enable proper QTL analysis (Table S4), although including these four distorted SNPs did not change the QTL mapping results. The final map consisted of 16 linkage groups, and the total length was $667.32 \mathrm{cM}$ with an average distance between markers of $7.3 \mathrm{cM}$ (Figure 2).

\section{3 $\quad$ QTL of asexual female functional virginity}

In total, 253 sex-asex introgressed females (221 G2 and $32 \mathrm{G} 4$ ) were genotyped (Figure 1, Table 1). QTL analysis identified a single QTL explaining $48.8 \%$ of the variation among females for the presence or absence of functional virginity (Figure 3), It was located on LG12 at $7 \mathrm{cM}$ (based on the EM algorithm) or $8 \mathrm{cM}$ (on the HK regression), with very high LOD values ( 41.3 and 40.8 respectively) (GLM model, $p<\mathrm{e}-16)$. No other significant QTL was detected across the genome above the $5 \%$ LOD threshold of $>2.51$, estimated from 1,000 permutations. Furthermore, no significant interactions of paired markers between linkage groups were detected, neither by the scantwo function nor by the multiple QTL function in R/QTL. The $95 \%$ confidence interval of the QTL location ranged between 4 and $10 \mathrm{cM}$ with the EM method and 6-11 cM with the HK method (Figure 3). The generation (BC2 or $\mathrm{BC} 4)$ was not a significant variable in the QTL model.

Two markers, Ajap26 (7-8 cM away from the QTL peak) and Ajap53 (7.9-8.9 cM away, Figure 3), delineate the QTL 95\% confidence intervals (4-11 cM from EM and HK model estimate). Females produced daughters (>80\%) when the markers were heterozygous (C:G for Ajap26 and A:T for Ajap53), and only sons when they were homozygous ( $G: G$ and $A: A$ respectively, which are the genotypes in the asexual strain; Figure 4). Note that, given the cross scheme (sex-asex introgressed females always mated to asexual males), the alternative homozygote $\mathrm{C}: \mathrm{C}$ or T:T (fixed for the sexual strain) did not occur in the sex-asex introgressed females. These results corroborate the prediction of a single recessive locus to be the determinant of female functional virginity (Ma et al., 2014a).

\subsection{Candidate gene analysis}

The assembled genome length is $271.51 \mathrm{Mb}$, suggesting that our PacBio genome assembly is $89.3 \%-96.4 \%$ complete (see Table 2 for additional statistics). Furthermore, BUSCO v3.0.1 identified $97 \%$ complete (C), 0.5\% fragmented (F), and $96.4 \%$ single-copy (S) genes. BUSCOs using the Insecta data set ( $n=1,658, C$ : $97.0 \%$ [S:96.4\%, D (duplicated):0.6\%], F:0.5\%, M (missing): $2.5 \%, n: 1,658$ ). The assembled transcriptome of $A$. tabida was composed of 34,140 transcripts longer than $300 \mathrm{bp}$, and 2,810 (8.2\%) transcripts were differentially expressed between the sexes with stringent criteria of $\left|\log _{2} \mathrm{FC}\right| \geq 2$ (Table S5).

The two SNP markers that identified the QTL mapped to two nonoverlapping contigs of the KG PacBio genome, contig0058 (1.78 Mb) and contig0035 (2.45 Mb). Based on the total genetic map length of $667.43 \mathrm{cM}$, assuming even marker density and using an estimated genome size 281.6-304.1 Mb, the two contigs comprise $58 \%-63 \%$ of the genomic region under the QTL peak. As female functional virginity trait (i.e., female resistance to mating) is probably a female-specific trait, we speculated that genes underlying its regulation may show sex-biased expression in sexual species. 
FIGURE 4 Genotype and associated proportion of successful mating for the introgressed sex-asex females at each of the two most closely linked markers flanking the detected QTL. Marker Ajap26 (a) and marker Ajap53 (b)
TABLE 2 Summary of the assembled PacBio genome of the asexual KG female of $A$. japonica
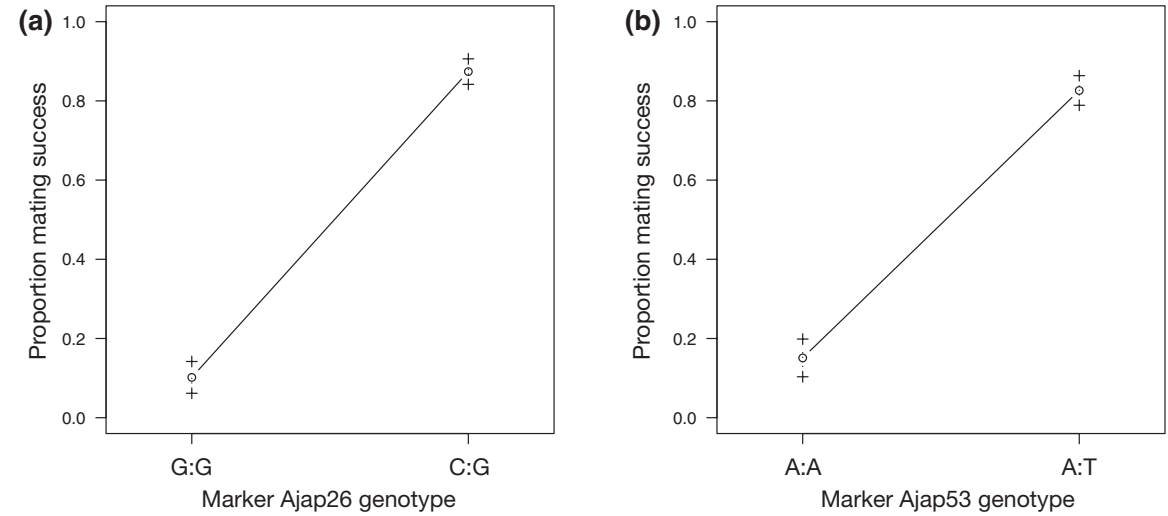

\begin{tabular}{|lll|}
\hline Size (bp)/category & Contig number & Total length (bp) \\
\hline$\geq 5,000$ & 739 & $271,381,159$ \\
$\geq 10,000$ & 656 & $270,751,034$ \\
\hline 25,000 & 471 & $267,578,667$ \\
\hline 250,000 & 375 & $264,211,158$ \\
\hline Longest & 1 & $5,810,954$ \\
\hline N75 & NA & 610,177 \\
\hline N50 & NA & $1,651,859$ \\
\hline GC\% & NA & $38.61 \%$ \\
\hline Total & 784 & $271,509,217$ \\
\hline
\end{tabular}

TAB LE 3 Among the total 131 candidate genes under the QTL (Table S6), 15 genes showed sex-biased expression in the sexual species Asobara tabida. All but one show female-biased expression

\begin{tabular}{|c|c|c|c|c|}
\hline Species & Gene/transcript & Gene function & Sex bias & Log2(male/female) \\
\hline A. japonica & transcript/543 & DNA replication ATP-dependent helicase/nuclease DNA2 & Female & -3.62 \\
\hline A. japonica & transcript/349 & Cordon-bleu protein-like 1 & Female & -4.2 \\
\hline A. japonica & transcript/4407 & Nuclear pore complex protein Nup $50^{\mathrm{b}}$ & Female & -11.04 \\
\hline A. japonica & transcript/1434 & Putative ankyrin repeat domain-containing protein 31 & Female & -3.88 \\
\hline A. japonica & transcript/15419 & Ubiquitin-conjugating enzyme E2 L3 & Female & -3.62 \\
\hline A. japonica & transcript/16014 & Vesicle-trafficking protein SEC22b-B & Female & -7.23 \\
\hline D. alloeum & XM_015253230.1 & Homeobox protein $\mathrm{Nkx}-6.2$ & Female & -3.6 \\
\hline F. arisanus & XM_011307786.1 & Hormone receptor 4 & Female & -3.56 \\
\hline F. arisanus & XM_011317030.1 & Open rectifier potassium channel protein 1 & Female & -4.85 \\
\hline
\end{tabular}

${ }^{a}$ Bold indicates shared putative candidate gene with differential expression between sexual and asexual stick insects in Timema (Parker et al., 2019). ${ }^{\mathrm{b}}$ Bold indicates shared putative candidate gene with mutations in asexual genome of Leptopilina clavipes (Kraaijeveld et al., 2016).

The two contigs associated with the QTL comprised 131 genes annotated with transcriptomes from different wasp species (Table S6). Among the 131 genes, several are encoding zinc finger proteins, ubiquitin-like proteins, protein kinase C-binding proteins, in addition to $23(18 \%)$ uncharacterized genes (Table S6). A total of 15 genes showed sex-biased expression in whole-body RNA libraries of the sexual species A. tabida (Table 3), of which 14 had higher expression in females. Two (CD151 antigen, nuclear pore complex protein Nup50) 
of these 15 sex-biased genes were also reported in previous studies (Table 3), in which genes were found to accumulate deleterious mutations following transitions from sexual reproduction to asexuality (Kraaijeveld et al., 2016), or showed differential expression between asexual and sexual sister species (Parker et al., 2019). Furthermore, hormone receptor 4 also showed significantly differential expression with female bias $\left(\log _{2}(\right.$ male/female $\left.)=-3.56\right)$. Null alleles, harboring a premature stop codon were detected in both the asexual $K G$ and sexual AM strain. A relatively higher density of SNPs between sexual and asexual $A$. japonica strains was found in the putative promoter region (up to $5 \mathrm{~kb}$ upstream of the start codon) compared to the intron and exon regions (Figure S2).

\section{4 | DISCUSSION}

Our aim was to investigate the genetic basis of female functional virginity in A. japonica. This required, as a first step, to generate a linkage map and genomic data sets that will be useful for comparative genomic studies across hymenopteran species. With an average intermarker distance of $7.3 \mathrm{cM}$, the $A$. japonica map has a comparable resolution to maps for other hymenopterans, including $4.0 \mathrm{cM}$ for the bumblebee Bombus terrestris (Stolle et al., 2011), 7.5 cM for the honeybee Apis mellifera (Solignac et al., 2004), 11.1 cM for Nasonia vitripennis (Pannebakker et al., 2011), $17.0 \mathrm{cM}$ for Bracon hebetor (Antolin et al., 1996) and 17.7 cM for Trichogramma brassicae (Laurent et al., 1998). Moreover, based on the estimated genome size of 281$304 \mathrm{Mb}$, the recombination rate of $A$. japonica is $2.20-2.37 \mathrm{cM} / \mathrm{Mb}$, compared to $\sim 1.5 \mathrm{cM} / \mathrm{Mb}$ for Nasonia (Pannebakker et al., 2011), $\sim 4.76 \mathrm{cM} / \mathrm{Mb}$ for Bombus terrestris (Stolle et al., 2011) and $22.8 \mathrm{cM} /$ Mb for Apis mellifera (Solignac et al., 2004). This, and the fact that the 16 linkage groups defined by the SNP map agree with earlier estimates of the number of chromosomes (12-17 chromosomes based on cytological data; Gokhman, 2009; G. Massimo, personal communication), indicate the accuracy of the constructed linkage map.

Our QTL analysis revealed that female functional virginity is associated with a single QTL with major effect. This is consistent with the previous prediction of a single recessive locus based on the segregation of phenotypes in our introgression lines (Ma et al., 2014a). In this previous study, Wolbachia-cured asexual females of A. japonica were found to have reduced attractiveness to males (only $55 \%$ asexual females attracted sexual males vs. 100\% sexual females), and a complete loss of mating acceptance resulting in a total absence of matings. As a result, these females produced only haploid sons (Ma et al., 2014a). The reduced attractiveness is probably not due to within-population mating preferences when this asexual population was sexual in the past, different from the situation reported from asexual Leptopilina wasps (Kraaijeveld et al., 2009). Indeed, in A. japonica, sexual females are equally attractive to sexual males and to males produced by asexual females, suggesting the reduced attractiveness in the reciprocal pairing is not due to lineage divergence between asexual and sexual strains (Ma et al., 2014a). Similar to our findings of a single QTL underlying female functional virginity, a simple genetic architecture for this trait was also found in two other studies of wasps with endosymbiont-induced asexuality. Inability to fertilize eggs segregated as expected for one or few loci with recessive effects in Telenomus nawai, and as expected for few loci with dominant effects in Trichogramma pretiosum with additional minoreffect modifiers (Jeong \& Stouthamer, 2005; Russell \& Stouthamer, 2011).

Our QTL analysis identified a single large-effect QTL on LG12 at 7 or $8 \mathrm{cM}(95 \% \mathrm{Cl}$ : 4-11 cM), strongly associated with female functional virginity. Annotation of the QTL region identified 131 physically-linked candidate genes. To our knowledge, this is the first study to identify candidate genes for female functional virginity, a trait that is predicted to evolve in the transition from sexuality to asexuality (Huigens \& Stouthamer, 2003). Because female functional virginity is female-specific, we hypothesized that the underlying gene(s) would show differential expression between sexes in sexual species. In total, 15 of the 131 genes were sex-biased in A. tabida, the sexual sister of $A$. japonica, and all but one had female-biased expression. The molecular changes in genes associated with the decay of sexual traits are still poorly known. A review (Arbuthnott, 2009) on the genetic architecture of sexual traits influencing premating isolation, such as behavioural signaling and courtship traits, found $69 \%$ ( 25 of 36 ) to be encoded by few loci with relatively large effects, and suggested changes in courtship behaviour may often evolve or decay quickly. Little is still known about the genetic basis of female receptivity, but auditory and/or olfactory receptors are likely candidates (Laturney \& Moehring, 2012). Among the 15 differentially expressed genes, gene functions are, among others, associated with hormone receptor, homeobox protein, ubiquitin-conjugating enzyme, nuclear pore complex protein, DNA replication ATP-dependent helicase. We further analysed hormone receptor 4 , because this gene encodes a steroid hormone receptor, and may therefore be relevant to mating resistance and female functional virginity. Hormone receptor 4 was shown to mediate the specific timing and expression of steroid hormone 20-hydroxyecdysone (20E) during the onset of metamorphosis in Drosophila and Lepidoptera (Kang et al., 2019; Ou et al., 2011). Steroid hormone $20 \mathrm{E}$ can be transferred from males to females during mating in the malaria mosquito Anopheles gambiae, leading to the loss of female receptivity to mating with other males (Gabrieli et al., 2014). It is thus possible that hormone receptor 4, among other steroid hormone receptors, interacts with steroid hormone $20 \mathrm{E}$ to induce the loss of mating receptivity in the malaria mosquito. Similar explanation could be applied to the asexual females of $A$. japonica with loss of mating propensity. We detected a premature stop codon in hormone receptor 4 in both the sexual and asexual strains. Moreover, we found multiple SNPs in the upstream (putative promoter) region, and in the gene itself, differentiating the sexual and asexual A. japonica strains. Further functional analyses are required to confirm this speculative role of hormone receptor 4 in female functional virginity of $A$. japonica.

Few studies have identified genes that are subject to change following transitions to asexuality. Kraaijeveld et al., (2016) compared genomes of sexual and asexual linages of the parasitoid wasp 
Leptopilina clavipes, and identified 16 genes with deleterious mutations (including frame shifts and early stop codons) associated with asexuality. One of our candidate genes, nuclear pore complex protein Nup50, was also among these 16 genes of L. clavipes. Nup50 is involved in mRNA transport, or positive regulation of transcription by RNA polymerase II and predominantly interacts with transcriptionally active genes inside the nucleoplasm, in particular those involved in developmental regulation and the cell cycle (Buchwalter et al., 2014; Kalverda et al., 2010). However, although this gene may be involved in the fertilization process, it probably does not directly cause female reluctance to mate, because asexual females mate readily but are unable to fertilize eggs in L. clavipes (Kraaijeveld et al., 2009, 2016). Another of our candidate genes, CD151 antigen, was also reported in a study identifying differential gene expression between females of sexual and asexual stick insects (Parker et al., 2019). CD151 antigen is a member of the transmembrane 4 superfamily, involved in cellular processes such as cell signalling, and may regulate integrin trafficking and function (Shigeta et al., 2003; Termini \& Gillette, 2017). In future studies, a near chromosomal-level genome assembly to completely cover the QTL region would be helpful to evaluate whether there are more candidate genes for female functional virginity in A. japonica. We were unable to improve our available genome assembly (e.g., bridge the large gap between the two contigs underlying the QTL) with the current data sets, and further scaffolding would require $\mathrm{Hi}-\mathrm{C}$ and/or optical mapping sequencing approaches (Belton et al., 2012; Howe \& Wood, 2015; Li et al., 2019). Meanwhile, functional analyses of the identified 131 candidate genes, especially the 15 ones with sex-biased expression, can be undertaken to further elucidate the molecular basis of female functional virginity in this species. Whether certain genes are particularly affected by a shift to asexuality requires more comparative studies on a broader array of species.

Sexual traits, including female mating behaviours, are costly, which may lead to such traits being selected against under asexuality (King \& Hurst, 2010; Russell \& Stouthamer, 2011; Stouthamer et al., 2010). Theoretical modeling of the spread of asexuality-inducing endosymbionts in mixed populations with uninfected and infected females, has confirmed that female functional virginity is favoured under sex-ratio selection (Stouthamer et al., 2010). Such selection might be stronger in haplodiploid species because unmated females will produce only haploid male progeny that balances the sex ratio. Once a mutation for rejection to mate has swept through an asexual population, the region comprising the genes associated with mating resistance does not get smaller, due to lack of recombination in asexuals. Moreover, this linked region may be maintained by selection if the trait has a polygenic basis. This may explain the large size of the single QTL detected in our study. Overall, our results are consistent with mutation(s) in the genomic region consisting of a single gene or a cluster of linked genes underlying rapid evolution of female functional virginity in the transition to asexuality.

\section{ACKNOWLEDGEMENTS}

We thank Rogier Houwerzijl and Peter Hes for assistance with wasp culturing, Ken Kraaijeveld, Barbara Reumer and Fabrice Favre for supplying A. japonica strains. We thank Marloes van Leussen for the PacBio DNA/RNA extractions, Fangying Chen for the wasp dissections and Klaas Vrieling for KASP analyses support, Mathijs Nas for performing the verification test of the in silico SNP markers, Bob Dröge and Aakrosh Ratan for assistance with the DIAL pipeline, and Bregje Wertheim for valuable discussions. We are indebted to three anonymous reviewers for their constructive comments. We acknowledge the DroParCon consortium (https://wiki.gcc.rug.nl/wiki/ DroparconStart) for providing Illumina short reads of both strains of $A$. japonica, this consortium was supported by Van Gogh grant to B. Pannebakker and Fabrice Vavre. W.-J. Ma was supported by an Ubbo Emmius Fellowship from the University of Groningen. X. Li was supported by China Scholarship Council (CSC) Scholarship no. 201606330077. This work was financed by grants no. 854.10 .001 and no. 824.15.015 from the Netherlands Organization for Scientific Research (NWO).

\section{AUTHOR CONTRIBUTIONS}

Conceptualization: W.-J.M., B.P., T.S., L.W.B., L.v.d.Z.. Data curation: W.-J.M., X.L., E.G., S.Y.A. Genome, transcriptome assembly and annotation: X.L., E.G., S. Y.A. Data analyses: W.-J.M., P.V. Funding acquisition: L.W.B., L.v.d.Z., T.S. Supervision: B.P., T.S., L.v.d.Z., L.W.B. Visualization: W.-J.M., P.V. Writing - original draft: W.-J.M. Writing - review \& editing: W.-J.M., P.V., L.W.B., T.S., L.v.d.Z., B.P., E.G., X.L., S.Y.A.

\section{DATA AVAILABILITY STATEMENT}

The data presented in this study can be accessed on NCBI Bioproject (PRJNA661661) with Accession nos SRR12618696-SRR12618699, JADHZF000000000, SAMN16067724, SAMN16067725). All relevant scripts and data files to perform these analyses have been deposited in Zenodo at https://doi.org/10.5281/zenodo.4557574, and Github at https://github.com/Wen-Juan/Decaytrait_qtl.

\section{ORCID}

Wen-Juan Ma (D) https://orcid.org/0000-0003-2585-6406

Bart A. Pannebakker (D) https://orcid.org/0000-0001-8503-3896

Paris Veltsos (D) https://orcid.org/0000-0002-8872-6281

Tanja Schwander (D) https://orcid.org/0000-0003-1945-5374

Louis van de Zande (D) https://orcid.org/0000-0001-5687-3220

Leo W. Beukeboom (D) https://orcid.org/0000-0001-9838-9314

\section{REFERENCES}

Aljanabi, S. M., \& Martinez, I. (1997). Universal and rapid salt-extraction of high quality genomic DNA for PCR-based techniques. Nucleic Acids Research, 25(22), 4692-4693.

Antolin, M. F., Bosio, C. F., Cotton, J., Sweeney, W., Strand, M. R., \& Black, W. C. (1996). Intensive linkage mapping in a wasp (Bracon hebetor) and a mosquito (Aedes aegypti) with single-strand conformation polymorphism analysis of random amplified polymorphic DNA markers. Genetics, 143, 1727-1738.

Arbuthnott, D. (2009). The genetic architecture of insect courtship behavior and premating isolation. Heredity, 103(1), 15-22. https://doi. org/10.1038/hdy.2009.22

Beavis, W. D. (1994). The power and deceit of QTL experiments: lessons from comparative QTL studies. Proceedings of the Forty-ninth Annual 
Corn and Sorghum Industry Research Conference ASTA, Washington. 250-266. https://www.ndsu.edu/pubweb/ mcclean/plsc731/ homework/papers/beavis\%20-\%20the\%20power\%20and\%20dec eit\%20of\%20qtl\%20experiments\%20-\%20lessons\%20from\%20 comparative\%20qt|\%20studies.pdf

Belton, J. M., McCord, R. P., Gibcus, J. H., Naumova, N., Zhan, Y., \& Dekker, J. (2012). Hi-C: A comprehensive technique to capture the conformation of genomes. Methods, 58(3), 268-276. https://doi. org/10.1016/j.ymeth.2012.05.001

Bolger, A. M., Lohse, M., \& Usadel, B. (2014). Trimmomatic: A flexible trimmer for Illumina sequence data. Bioinformatics, 30(15), 21142120. https://doi.org/10.1093/bioinformatics/btu170

Bray, N., Pimentel, H., Melsted, P., \& Pachter, L. (2016). Near-optimal RNA-Seq quantification. Nature Biotechnology, 34(5), 525-528. arXiv:1505.02710

Broman, K. W., \& Sen, S. (2009). A guide to QTL mapping with R/qtl. Statistics for Biology and Health, 1edn, New York, NY: Springer. https://doi.org/10.1007/978-0-387-92125-9

Broman, K. W., Wu, H., Sen, Ś., \& Churchill, G. A. (2003). R/qtl: QTL mapping in experimental crosses. Bioinformatics, 19(7), 889-890. https://doi.org/10.1093/bioinformatics/btg112

Buchwalter, A. L., Liang, Y., \& Hetzer, M. W. (2014). Nup50 is required for cell differentiation and exhibits transcription-dependent dynamics. Molecular Biology of the Cell, 25(16), 2472-2484. https://doi. org/10.1091/mbc.E14-04-0865

Carson, H. L., Chang, L. S., \& Lyttle, T. W. (1982). Decay of female sexual behavior under parthenegenesis. Science, 218(4567), 68-70.

Chen, Y., Lun, A. T. L., \& Smyth, G. K. (2016). From reads to genes to pathways: Differential expression analysis of RNA-Seq experiments using Rsubread and the edgeR quasi-likelihood pipeline. F1000Research, 5, 1438. https://doi.org/10.12688/f1000resea rch.8987.1

Chin, C.-S., Alexander, D. H., Marks, P., Klammer, A. A., Drake, J., Heiner C., Clum, A., Copeland, A., Huddleston, J., Eichler, E. E., Turner, S. W., \& Korlach, J. (2013). Nonhybrid, finished microbial genome assemblies from long-read SMRT sequencing data. Nature Methods, 10(6), 563-569. https://doi.org/10.1038/nmeth.2474

Chin, C.-S., Peluso, P., Sedlazeck, F. J., Nattestad, M., Concepcion, G. T., Clum, A., \& Schatz, M. C. (2016). Phased diploid genome assembly with single molecule real-time sequencing. Nature Methods, 13(2), 1050-1054. https://doi.org/10.1097/CCM.0b013e31823da96d. Hydrogen

Dedeine, F., Vavre, F., Fleury, F., Loppin, B., Hochberg, M. E., \& Boulétreau, M. (2001). Removing symbiotic Wolbachia bacteria specifically inhibits oogenesis in a parasitic wasp. Proceedings of the National Academy of Sciences, 98(11), 6247-6252. https://doi.org/10.1073/ pnas. 101304298

Gabrieli, P., Kakani, E. G., Mitchell, S. N., Mameli, E., Want, E. J., Anton, A. M., \& Catteruccia, F. (2014). Sexual transfer of the steroid hormone $20 \mathrm{E}$ induces the postmating switch in Anopheles gambiae. Proceedings of the National Academy of Sciences of the United States of America, 111(46), 16353-16358. https://doi.org/10.1073/ pnas.1410488111

Giorgini, M., Bernardo, U., Monti, M. M., Nappo, A. G., \& Gebiola, M. (2010). Rickettsia symbionts cause parthenogenetic reproduction in the parasitoid wasp Pnigalio soemius (Hymenoptera: Eulophidae). Applied and Environmental Microbiology, 76(8), 2589-2599. https:// doi.org/10.1128/AEM.03154-09

Gokhman, V. E. (2009). Karyotypes of parasitic hymenoptera. 1, Dordrecht, The Netherlands: Springer, Dordrecht. https://doi. org/10.1007/978-1-4020-9807-9

Gordon, S. P., Tseng, E., Salamov, A., Zhang, J., Meng, X., Zhao, Z., Kang, D., Underwood, J., Grigoriev, I. V., Figueroa, M., Schilling, J. S., Chen, F., \& Wang, Z. (2015). Widespread polycistronic transcripts in fungi revealed by single-molecule mRNA sequencing. PLoS One, 10(7), 1-15. https://doi.org/10.1371/journal.pone.0132628
Gottlieb, Y., \& Zchori-Fein, E. (2001). Irreversible thelytokous reproduction in Muscidifurax uniraptor. Entomologia Experimentalis Et Applicata, 100, 271-278.

Gotz, S., Garcia-Gomez, J. M., Terol, J., Williams, T. D., Nagaraj, S. H., Nueda, M. J., Robles, M., Talon, M., Dopazo, J., \& Conesa, A. (2008). High-throughput functional annotation and data mining with the Blast2GO suite. Nucleic Acids Research, 36(10), 3420-3435. https:// doi.org/10.1093/nar/gkn176

Gurevich, A., Saveliev, V., Vyahhi, N., \& Tesler, G. (2013). QUAST: Quality assessment tool for genome assemblies. Bioinformatics, 29(8), 1072-1075. https://doi.org/10.1093/bioinformatics/btt086

Haas, B. J., Papanicolaou, A., Yassour, M., Grabherr, M., Blood, P. D., Bowden, J., Couger, M. B., Eccles, D., Li, B. O., Lieber, M., MacManes, M. D., Ott, M., Orvis, J., Pochet, N., Strozzi, F., Weeks, N., Westerman, R., William, T., Dewey, C. N., ... Regev, A. (2013). De novo transcript sequence reconstruction from RNA-seq using the Trinity platform for reference generation and analysis. Nature Protocols, 8(8), 14941512. https://doi.org/10.1038/nprot.2013.084

Haley, C. S., \& Knott, S. A. (1992). A simple regression method for mapping quantitative trait loci in line crosses using flanking markers. Heredity, 69(4), 315-324. https://doi.org/10.1038/hdy.1992.131

Heath, B. D., Butcher, R. D. J., Whitfield, W. G. F., \& Hubbard, S. F. (1999). Horizontal transfer of Wolbachia between phylogenetically distant insect species by a naturally occuring mechanism. Current Biology, 9, 313-316.

Howe, K., \& Wood, J. M. D. (2015). Using optical mapping data for the improvement of vertebrate genome assemblies. GigaScience, 4, 10. https://doi.org/10.1186/s13742-015-0052-y

Huigens, M. E., \& Stouthamer, R. (2003). Parthenogenesis associated with Wolbachia. In K. Bourtzis, \& T. A. Miller (Eds.), Insect symbiosis (pp. 247-266). CRC Press.

Jeong, G., \& Stouthamer, R. (2005). Genetics of female functional virginity in the parthenogenesis-Wolbachia infected parasitoid wasp Telenomus nawai (Hymenoptera: Scelionidae). Heredity, 94(4), 402407. https://doi.org/10.1038/sj.hdy.6800617

Kageyama, D., Narita, S., \& Watanabe, M. (2012). Insect sex determination manipulated by their endosymbionts: incidences, mechanisms and implications. Insects, 3(10), 161-199. https://doi.org/10.3390/ insects3010161

Kalverda, B., Pickersgill, H., Shloma, V. V., \& Fornerod, M. (2010). Nucleoporins directly stimulate expression of developmental and cell-cycle genes inside the nucleoplasm. Cell, 140(3), 360-371. https://doi.org/10.1016/j.cell.2010.01.011

Kang, X.-L., Zhang, J. Y., Wang, D., Zhao, Y. M., Han, X. L., Wang, J. X., \& Zhao, X. F. (2019). The steroid hormone 20-hydroxyecdysone binds to dopamine receptor to repress lepidopteran insect feeding and promote pupation. PLoS Genetics, 15, E1008331. https://doi. org/10.1371/journal.pgen.1008331

King, K. C., \& Hurst, G. D. D. (2010). Losing the desire: selection can promote obligate asexuality. BMC Biology, 8, 8-10. https://doi. org/10.1186/1741-7007-8-101

Kosambi, D. D. (1943). The estimation of map distances from recombination values. Annals of Human Genetics, 12(1), 172-175.

Kraaijeveld, K., Anvar, Y., Frank, J., Schmitz, A., Bast, J., Wilbrandt, J., Petersen, M., Ziesmann, T., Niehuis, O., Knijff, P. D., Dunnen, J. T. D., $\&$ Ellers, J. (2016). Decay of sexual trait genes in an asexual parasitoid wasp. Genome Biology and Evolution, 8(12), 3685-3695. https:// doi.org/10.1093/gbe/evw273

Kraaijeveld, K., Franco, P., Reumer, B. M., \& Van Alphen, J. J. M. (2009). Effects of parthenogenesis and geographic isolation on female sexual traits in a parasitoid wasp. Evolution, 63(12), 3085-3096. https://doi.org/10.1111/j.1558-5646.2009.00798.x

Kraaijeveld, K., Reumer, B. M., Mouton, L., Kremer, M., Vavre, F., \& van Alphen, J. J. (2011). Does a parthenogenesis-inducing Wolbachia induce vestigial cytoplasmic incompatibility ? Naturwissenschaften, 98, 175-180. https://doi.org/10.1007/s00114-010-0756-x 
Kremer, N., Charif, D., Henri, H., Bataille, M., Prévost, G., Kraaijeveld, K., \& Vavre, F. (2009). A new case of Wolbachia dependence in the genus Asobara: Evidence for parthenogenesis induction in Asobara japonica. Heredity, 103, 248-256. https://doi.org/10.1038/ hdy. 2009.63

Laturney, M., \& Moehring, A. J. (2012). Fine-scale genetic analysis of species-specific female preference in Drosophila simulans. Journal of Evolutionary Biology, 25(9), 1718-1731. https://doi. org/10.1111/j.1420-9101.2012.02550.x

Laurent, V., Wajnberg, E., Mangin, B., Schiex, T., Gaspin, C., \& Vanlerberghe-Masutti, F. (1998). A composite genetic map of the parasitoid wasp Trichogramma brassicae based on RAPD markers. Genetics, 150(1), 275-282.

Leach, I. M., Pannebakker, B. A., Schneider, M. V., Driessen, G., Van de Zande, L., \& Beukeboom, L. W. (2009). Thelytoky in Hymenoptera with Venturia canescens and Leptopilina clavipes as case studies. In I. Schön, I. Martens, \& P. Dijk (Eds.), Lost sex (pp. 347-375). Springer, Dordrecht.

Li, H., \& Durbin, R. (2009). Fast and accurate short read alignment with Burrows-Wheeler transform. Bioinformatics, 25(14), 1754-1760. https://doi.org/10.1093/bioinformatics/btp324

Li, H., Handsaker, B., Wysoker, A., Fennell, T., Ruan, J., Homer, N., Marth, G., Abecasis, G., \& Durbin, R. (2009). The sequence alignment/map format and SAMtools. Bioinformatics, 25(16), 2078-2079. https:// doi.org/10.1093/bioinformatics/btp352

Li, Y., Ren, Y., Zhang, D., Jiang, H., Wang, Z., Li, X., \& Rao, D. I. (2019). Chromosome-level assembly of the mustache toad genome using third-generation DNA sequencing and $\mathrm{Hi}-\mathrm{C}$ analysis. GigaScience, 8(9), giz114. https://doi.org/10.1093/gigascience/giz114

Lorieux, M. (2012). MapDisto: Fast and efficient computation of genetic linkage maps. Molecular Breeding, 30(2), 1231-1235. https://doi. org/10.1007/s11032-012-9706-y

Ma, W.-J. (2014). Evolutionary genetics of Wolbachia-induced parthenogenesis in the parastioid Asobara japonica. PhD thesis. Groningen, The Netherlands: University of Groningen https://research.rug.nl/ files/14992319/Complete_original.pdf

Ma, W.-J., Kuijper, B., de Boer, J. G., van de Zande, L., Beukeboom, L. W., Wertheim, B., \& Pannebakker, B. A. (2013). Absence of complementary sex determination in the parasitoid wasp genus Asobara (Hymenoptera: Braconidae). PLoS One, 8(4), e60459. https://doi. org/10.1371/journal.pone.0060459

Ma, W.-J., Pannebakker, B. A., Beukeboom, L. W., Schwander, T., \& van de Zande, L. (2014a). Genetics of decayed sexual traits in a parasitoid wasp with endosymbiont-induced asexuality. Heredity, 113(5), 424431. https://doi.org/10.1038/hdy.2014.43

Ma, W.-J., Vavre, F., \& Beukeboom, L. W. (2014b). Manipulation of arthropod sex determination by endosymbionts: Diversity and mo lecular mechanisms. Sexual Development, 8, 59-73. https://doi. org/10.1159/000357024

Ma, W. J., Pannebakker, B. A., Beukeboom, L. W., Schwander, T., \& van de Zande, L. (2014c). Data from: Genetics of decayed sexual traits in a parasitoid wasp with endosymbiont-induced asexuality. Dataset, https://doi.org/10.5061/dryad.rfobh

Ma, W.-J., Pannebakker, B. A., Van De Zande, L., Schwander, T., Wertheim, B., \& Beukeboom, L. W. (2015). Diploid males support a two-step mechanism of endosymbiont-induced thelytoky in a parasitoid wasp. BMC Evolutionary Biology, 15, 84. https://doi.org/10.1186/ s12862-015-0370-9

Ma, W.-J., \& Schwander, T. (2017). Patterns and mechanisms in instances of endosymbiont-induced parthenogenesis. Journal of Evolutionary Biology, 30(5), 868-888.

Ma, W.-J., Veltsos, P., Sermier, R., Parker, D. J., \& Perrin, N. (2018) Evolutionary and developmental dynamics of sex-biased gene expression in common frogs with proto-Y chromosomes. Genome Biology, 19, 156. https://doi.org/10.1186/s13059-018-1548-4
Ma, W.-J., Veltsos, P., Toups, M. A., Rodrigues, N., Sermier, R., Jeffries, D. L., \& Perrin, N. (2018). Tissue specificity and dynamics of sexbiased gene expression in a common frog population with differentiated, yet homomorphic, sex chromosomes. Genes, 9, 294. https:// doi.org/10.3390/genes 9060294

Marçais, G., \& Kingsford, C. (2011). A fast, lock-free approach for efficient parallel counting of occurrences of k-mers. Bioinformatics, 27(6), 764-770. https://doi.org/10.1093/bioinformatics/btr011

Marshall, O. J. (2004). PerlPrimer: Cross-platform, graphical primer design for standard, bisulphite and real-time PCR. Bioinformatics, 20(15), 2471-2472. https://doi.org/10.1093/bioinformatics/ bth254

McCarthy, D. J., Chen, Y., \& Smyth, G. K. (2012). Differential expression analysis of multifactor RNA-Seq experiments with respect to biological variation. Nucleic Acids Research, 40(10), 4288-4297. https://doi.org/10.1093/nar/gks042

Murata, Y. U., Ideo, S. H., Watada, M. A., Mitsui, H. I., \& Kimura, M. A. T. (2009). Genetic and physiological variation among sexual and parthenogenetic populations of Asobara japonica (Hymenoptera : Braconidae), a larval parasitoid of drosophilid flies. European Journal of Entomology, 5759, 171-178.

Narasimhan, V., Danecek, P., Scally, A., Xue, Y., Tyler-Smith, C., \& Durbin, R. (2016). BCFtools/RoH: A hidden Markov model approach for detecting autozygosity from next-generation sequencing data. Bioinformatics, 32(11), 1749-1751. https://doi.org/10.1093/bioin formatics/btw044

Ou, Q., Magico, A., \& King-Jones, K. (2011). Nuclear receptor DHR4 controls the timing of steroid hormone pulses during Drosophila development. PLOS Biology, 9(9), e1001160. https://doi.org/10.1371/ journal.pbio.1001160

Pannebakker, B. A., Schidlo, N. S., Boskamp, G. J. F., Dekker, L., Van Dooren, T. J. M., Beukeboom, L. W., Zwaan, B. J., Brakefield, P. M., \& van Alphen, J. J. M. (2005). Sexual functionality of Leptopilina clavipes (Hymenoptera : Figitidae) after reversing Wolbachia -induced parthenogenesis. Journal of Evolutionary Biology, 18, 1019-1028. https://doi.org/10.1111/j.1420-9101.2005.00898.x

Pannebakker, B. A., Watt, R., Knott, S. A., West, S. A., \& Shuker, D. M. (2011). The quantitative genetic basis of sex ratio variation in Nasonia vitripennis: A QTL study. Journal of Evolutionary Biology, 24(1), 12-22. https://doi.org/10.1111/j.1420-9101.2010.02129.x

Parker, D. J., Bast, J., Jalvingh, K., Dumas, Z., Robinson-Rechavi, M. \& Schwander, T. (2019). Repeated evolution of asexuality involves convergent gene expression changes. Molecular Biology and Evolution, 36(2), 350-364. https://doi.org/10.1093/molbev/ msy217

Pijls, J. W. A. M., van Steenbergen, H. J., \& van Alphen, J. J. M. (1996). Asexuality cured: the relations and differences between sexual and asexual Apoanagyrus diversicornis. Heredity, 76, 506-513.

R Core Team. (2020). R: A language and environment for statistical computing. R Foundation for Statistical Computing, Vienna, Austria: R Core Team. https://www.R-project.org/

Ratan, A., Zhang, Y., Hayes, V. M., Schuster, S. C., \& Miller, W. (2010). Calling SNPs without a reference sequence. BMC Bioinformatics, 11 130. https://doi.org/10.1186/1471-2105-11-130

Reumer, B. M., van Alphen, J. J. M., \& Kraaijeveld, K. (2012). Occasional males in parthenogenetic populations of Asobara japonica (Hymenoptera: Braconidae): low Wolbachia titer or incomplete coadaptation? Heredity, 108(3), 341-346. https://doi.org/10.1038/ hdy.2011.82

Robinson, M. D., Mccarthy, D. J., \& Smyth, G. K. (2010). edgeR: A Bioconductor package for differential expression analysis of digital gene expression data. Application Note, 26(1), 139-140. https://doi. org/10.1093/bioinformatics/btp616

Russell, J. E., \& Stouthamer, R. (2011). The genetics and evolution of obligate reproductive parasitism in Trichogramma pretiosum infected 
with parthenogenesis-inducing Wolbachia. Heredity, 106(1), 58-67. https://doi.org/10.1038/hdy.2010.48

Schwander, T., Crespi, B. J., Gries, R., \& Gries, G. (2013). Neutral and selection-driven decay of sexual traits in asexual stick insects. Proceedings of the Royal Society B, 280, 20130823.

Semagn, K., Babu, R., Hearne, S., \& Olsen, M. (2014). Single nucleotide polymorphism genotyping using Kompetitive Allele Specific PCR (KASP): Overview of the technology and its application in crop improvement. Molecular Breeding, 33(1), 1-14. https://doi. org/10.1007/s11032-013-9917-x

Shigeta, M., Sanzen, N., Ozawa, M., Gu, J., Hasegawa, H., \& Sekiguchi, K. (2003). CD151 regulates epithelial cell-cell adhesion through PKCand Cdc42-dependent actin cytoskeletal reorganization. Journal of Cell Biology, 163(1), 165-176. https://doi.org/10.1083/jcb.20030 1075

Simão, F. A., Waterhouse, R. M., Ioannidis, P., Kriventseva, E. V., \& Zdobnov, E. M. (2015). BUSCO: Assessing genome assembly and annotation completeness with single-copy orthologs. Bioinformatics, 31(19), 3210-3212. https://doi.org/10.1093/bioin formatics/btv351

Solignac, M., Vautrin, D., Baudry, E., Mougel, F., Loiseau, A., \& Cornuet, J. M. (2004). A microsatellite-based linkage map of the honeybee, Apis Mellifera L. Genetics, 167(1), 253-262. https://doi.org/10.1534/ genetics.167.1.253

Stolle, E., Wilfert, L., Schmid-Hempel, R., Schmid-Hempel, P., Kube, M., Reinhardt, R., \& Moritz, R. F. A. (2011). A second generation genetic map of the bumblebee Bombus terrestris (Linnaeus, 1758) reveals slow genome and chromosome evolution in the Apidae. BMC Genomics, 12(1), 48. https://doi.org/10.1186/1471-2164-12-48

Stouthamer, R., \& Kazmer, D. J. (1994). Cytogenetics of microbeassociated parthenogenesis and its consequences for gene flow in Trichogramma wasps. Heredity, 73, 317-327.

Stouthamer, R., Russell, J. E., Vavre, F., \& Nunney, L. (2010). Intragenomic conflict in populations infected by parthenogenesis inducing Wolbachia ends with irreversible loss of sexual reproduction. BMC Evolutionary Biology, 10, 229. https://doi. org/10.1186/1471-2148-10-229
Termini, C. M., \& Gillette, J. M. (2017). Tetraspanins function as regulators of cellular signaling. Frontiers in Cell and Developmental Biology, 5, 34. https://doi.org/10.3389/fcell.2017.00034

van der Kooi, C. J., \& Schwander, T. (2014). On the fate of sexual traits under asexuality. Biological Reviews, 89(4), 805-819. https://doi. org/10.1111/brv.12078

Voorrips, R. E. (2002). MapChart: Software for the graphical presentation of linkage maps and QTLs. Journal of Heredity, 93(1), 77-78. https://doi.org/10.1093/jhered/93.1.77

Vurture, G. W., Sedlazeck, F. J., Nattestad, M., Underwood, C. J., Fang, H., Gurtowski, J., \& Schatz, M. C. (2017). GenomeScope: Fast referencefree genome profiling from short reads. Bioinformatics, 33(14), 2202-2204. https://doi.org/10.1093/bioinformatics/btx153

Werren, J. H. (1997). Biology of Wolbachia. Annual Review of Entomology, 42, 587-609.

Werren, J. H., Baldo, L., \& Clark, M. (2008). Wolbachia: Master manipulators of invertebrate biology. Nature Reviews Microbiology, 6, 741-751.

Whiting, P. W. (1933). Selective fertilization and sex-determination in Hymenoptera. Science, 78, 537-538. https://doi.org/10.1126/scien ce.78.2032.537-a

Wu, T. D., \& Watanabe, C. K. (2005). GMAP: a genomic mapping and alignment program for mRNA and EST sequences. Bioinformatics, 21(9), 1859-1875. https://doi.org/10.1093/bioinformatics/bti310.

\section{SUPPORTING INFORMATION}

Additional supporting information may be found online in the Supporting Information section.

How to cite this article: Ma W-J, Pannebakker BA, Li X, et al. A single QTL with large effect is associated with female functional virginity in an asexual parasitoid wasp. Mol Ecol. 2021;30:1979-1992. https://doi.org/10.1111/mec.15863 